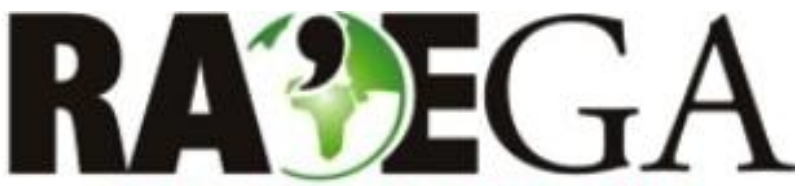

O ESPACO GEOGRÁFICO EM ANÁLISE

\title{
SIGLO DELEUZIANO, SIGLO DE LOS MAPAS: CUALIDADES, SENTIDOS Y PROCESOS PUESTOS EN JUEGO EN LAS CARTOGRAFÍAS DE LA SUBJETIVIDAD
}

\section{DELEUZIAN CENTURY, CENTURY OF MAPS: QUALITIES, MEANINGS AND PROCESSES AT STAKE IN THE CARTOGRAPHIES OF SUBJECTIVITY}

\author{
Eduardo Álvarez Pedrosian \\ Pós-Doutorando em Antropología pela Universidade de São Paulo (USP) \\ Departamento de Ciencias Humanas y Sociales \\ Universidad de la República \\ Montevidéu, Uruguai \\ e-mail: eduardo.alvarez@comunicacion.edu.uy
}

\section{Recebido em: 30/08/2013}

Aceito em: 04/01/2014

\section{Resumo}

A frase de Foucault de que nosso século seria um "século deleuziano" pode ser entendido como um "século de mapas", de cartografias da subjetividade. O interesse pela forma em que se cria o universo que habitamos, a elaboração de um pensamento em devir e o múltiplo que sempre procura fugir das essências tem no mapeamento um foco de interesse privilegiado e é o nosso propósito expor as conexões conceituais que suportam e potencializam esta perspectiva. Para isso, propomos primeiro as realizações entre as correntes do estruturalismo, pósestruturalismo e "pensamento de fora" para caracterizar esse último de uma forma mais certeira possível, tanto epistemologicamente como ontologicamente, encaminhando-os em direção do conceito de cartografia, implantado neste contexto em relação aos seus antecedentes. Posteriormente trabalhamos as relações entre arte, ciência e filosofia na produção destas cartografias dos processos de subjetivação como forma de ser a partir de práticas, abordadas etnograficamente, para caracterizar as qualidades, os sentidos e processos em jogo. E por último, propomos os elementos e formas de composição dessas cartografias, considerando variações como o diagrama, rizoma, colcha de retalhos, moldura e script audiovisual, tratando de temas como o espaço-tempo e a criatividade e considerando as propostas recentes que a partir da geografia, por sua vez, têm mostrado o seu interesse na filosofia de Deleuze, Guattari e Foucault ou nos problemas do mapeamento em termos mais gerais 
Siglo deleuziano, siglo de los mapas: cualidades, sentidos y procesos puestos en juego en las cartografías de la subjetividad

Palavras-chave: pensamento nômade; cartografia; rizoma; processos de subjetivação; etnografia experimental.

\begin{abstract}
Foucault's phrase about our century being a "Deleuzian's century" can be understood as a "century of maps", of the cartographies of subjectivity. The interest in the form that creates the universe that we live in, the elaboration of a thought about becoming and the multiple that always seeks to escape from the essences have mapping as a focus of privileged interest. It is our proposal to reveal the conceptual connections that support and potentialize this perspective. For this purpose, we first point out the relations between the so-called terms structuralism, post-structuralism and "thought from outside" in order to characterize the latter in the best possible manner, both epistemologically and ontologically, directing them towards the concept of cartography, implanted in this context in relation to its forerunners. In the next step we work with the relationships between art, science and philosophy in the production of these cartographies of subjectivation processes as forms derived from practice, approached in an ethnographic way, in order to characterize the qualities, senses and processes at stake. And finally, we will propose the elements and forms of composition of cartographies, considering variations such as the diagram, rhizome, patchwork, framing and audiovisual script, addressing topics such as space-time and creativity, and considering recent proposals from the standpoint of geography that have shown their interest in the philosophy of Deleuze, Guattari and Foucault or in the problems of mapping in more general terms.
\end{abstract}

Keywords: nomadic thought; cartography: rhizome; processes of subjectivation; experimental ethnography.

INTRODUCCIÓN: ESTRUCTURALISMO, POS-ESTRUCTURALISMO Y PENSAMIENTO DEL AFUERA

El llamado pensamiento estructuralista, en auge a mediados del siglo $X X$, no constituyó una empresa explícitamente definida por aquellos investigadores más directamente asociados al mismo. Más aún, Lévi-Strauss o Lacan se negaban a ser calificados bajo tal rótulo, a la par que encontraban grandes discrepancias entre sus planteos y los de otras figuras intelectuales de la época. Lo cierto es que el estructuralismo se constituyó en un movimiento sin timón, un gran programa de investigación (LAKATOS, 1989), aunque sin planificación consciente, pero que superó ampliamente los límites disciplinares y los existentes entre el conocimiento científico y el pensamiento filosófico. Inevitablemente constituyó para muchos una 
Siglo deleuziano, siglo de los mapas: cualidades, sentidos y procesos puestos en juego en las cartografías de la subjetividad

suerte de gran paradigma civilizatorio, en el sentido en que Morin (1992) amplía la noción que rápidamente Kuhn abandonara gracias a las tempranas acusaciones de irracionalismo (léase intereses sospechosos en el contexto anglosajón de entonces).

Esta especie de negación, por parte de quienes fueron identificados como los mayores exponentes de esta concepción (llamados hasta de "padres" como en el caso de Lévi-Strauss), puede entenderse de varias formas. Simplificando la cuestión, por un lado podemos apreciar la efectiva diversidad de visiones que caían en su seno y los duros debates que se daban por entonces en el contexto de la academia francesa previa al mayo del '68, y por otro una suerte de estrategia muy inteligente y coherente con la propia concepción en cuestión: el estructuralismo está en todas y en ninguna parte, al igual que las estructuras así concebidas. $Y$ efectivamente, a pesar de las derivas y los senderos de las diferentes teorías existentes en el amplio volumen epistemológico de las llamadas ciencias humanas y sociales, es impensable el presente sin haber existido el estructuralismo. Sin querer ser evolucionista, podemos igualmente afirmar que después de él no hay marcha atrás. Interesante resulta que a partir de sus más radicales críticos, entre ellos los pensados que aquí más nos interesan, es que es conocido en el mundo anglosajón. No olvidemos que para los llamados "cultural studies" norteamericanos, Lacan, Derrida o Foucault forman parte de un mismo paquete, el llamado "pensamiento francés".

Para los intereses de nuestro trabajo, podemos plantear una serie de principios que definen la perspectiva estructuralista, y cómo a partir de su crítica se desprenden las visiones tan reveladoras como las de Foucault, Deleuze y Guattari. Para ello podemos servirnos de un texto canónico del mismo Lévi-Strauss, La noción de estructura en etnología, y con ello entender la manera de pensar estructuralista a partir de cómo se concibe la estructura (LÉVI-STRAUSS, 1994b, p.301). En primer lugar, cualquier cosa que consideramos estructura nos exige pensar en las relaciones dentro de un sistema. Se trata efectivamente de una visión relacional en esencia; los términos pasan de ser las antiguas unidades a ser los nexos entre estas. En una red, todo está conectado con todo, a pesar de tratarse de una taxonomía. En tal sentido, aunque la estructura sea considerada a partir de elementos binarios y según la simetría arborescente, la condición relacional nos 
Siglo deleuziano, siglo de los mapas: cualidades, sentidos y procesos puestos en juego en las cartografías de la subjetividad

exige pensar de tal forma que cada cambio en uno de los elementos implica la transformación de la totalidad.

En segundo lugar, existe estructura más allá de las dinámicas que puedan apreciarse, en una lógica combinatoria que intenta superar la distinción entre lo diacrónico y lo sincrónico, en pos de este último: toda estructura está estructuralmente pautada por series de transformaciones, modelos de variación igual de ordenados, coherentes y eficazmente reproducibles. En tercer lugar, esta perspectiva formalista y totalizadora, compartirá con el positivismo la noción de ciencia y pensamiento racional para el cual es necesario poder realizar las predicciones a los cambios venideros, gracias al conocimiento de lo que terminan siendo un conjunto finito de leyes que estructuran el universo, tanto humano como no-humano. Por último, el modelo construido debe dar cuenta de todos los hechos observados, es decir, debe ser exhaustivo.

Inmerso en el llamado giro lingüístico, y siendo un agente fundamental en la expansión del mismo, el modelo formalista de la lingüística de Saussure fue la base para la concepción de cualquier entidad de estudio relativa al ser humano y sus producciones. Todo lo relativo al mundo humano puede ser leído como un conjunto de sistemas, a partir de la conformación del signo y sus dos caras, la que mira hacia el interior de la naturaleza humana (significante) y la que lo hace hacia el mundo más allá de la misma (el significado), en un nexo donde la primera está inexorablemente dentro de la segunda, pero donde es posible una suerte de toma de conciencia, una asunción del espíritu en el cosmos, al estilo del trascendentalismo hegeliano, por supuesto el cartesianismo, y más de fondo el platonismo y su concepción del mundo de las ideas, los modelos abstractos y el poder de la mente. A esta vertiente lingüística, hay que sumarle la tradición de la escuela sociológica francesa, y en especial la versión del positivismo sofisticado de la sociología de Durkheim, de gran impacto en las mismas décadas de comienzo del siglo XX.

Entender a lo social como aquello que tiene un orden perdurable, una configuración reproducible, y que la misma tiene la fuerza de una ley natural, de la cohesión que obliga a cualquier espécimen a acatarla (una "institución"), se combina con lo anterior, dando como resultado el estudio de cualquier "hecho social" como un "sistema de significación". A ello hay que sumarle un tercer elemento constituyente 
Siglo deleuziano, siglo de los mapas: cualidades, sentidos y procesos puestos en juego en las cartografías de la subjetividad

de esta suerte de programa de investigación: el inconsciente. Estas estructuras que configuran toda existencia y por tal motivo se les puede otorgar tal carácter (de ente que existe: una sociedad, una cultura, un espacio habitado, etc.), se dan a todos los niveles y fundamentalmente operan en el inconsciente, más allá de la claridad y el control de la racionalidad. El simbolismo define la operación de creación de cultura por excelencia: además de fonemas y morfemas hay "mitemas", y otras configuraciones semiológicas, que funcionan como estabilizadoras del sentido, desacelerando el caos y poniendo en orden las palabras y las cosas.

El estructuralismo parece estar en vías de dejar de ser el
protagonista para convertirse en la escena en cuyo espacio todos o
casi todos los papeles clásicos se vuelven a representar. [...]
Diremos -y es la única manera de no caer en la confusión- que con
el nombre de estructuralismo se reagrupan las ciencias del signo, de
los sistemas de signos. Los hechos antropológicos más diversos
pueden entrar en él, pero sólo en tanto pasan por los hechos de la
lengua -en tanto están comprendidos en la institución de un sistema
del tipo significante/significado y se adaptan a la red de una
comunicación-y de allí reciben su estructura (WAHL, 1975, p.11-13).

Ahora bien, sobre esta matriz tan poderosa elaborada por los investigadores en etnología, lingüística, semiología, sociología y economía política, sumando elementos del materialismo histórico o no, dialogando problemáticamente con la fenomenología existencialista francesa (Sartre, Merleau-Ponty), el pensamiento estructuralista se enfrenta a una nueva generación a partir de fines de los años sesenta del siglo pasado, para la cual se hace necesario superar la suerte de absolutización a la que arribara sin remedio. $Y$ es que si bien el formalismo tan elaborado por esta perspectiva constituye un ataque radical contra cualquier forma de sustancialismo (donde la naturaleza humana quede fijada y asociada a contenidos trascendentes, esencias sustentadas en creencias siempre transitorias), no deja de ser una nueva sustancialización, pero sin contenido, y por tanto de la forma. Un sujeto trascendental, ya planteado en la filosofía kantiana, anteriormente fundante del racionalismo cartesiano, sostenido en un espíritu en tanto mecanismo de identificación de las estructuras que ordenan el mundo, existentes a priori y construidas a posteriori, se yergue como la entidad objetivable por unas ciencias que, para retomar la clásica expresión de Lévi-Strauss, "disuelven al sujeto". 
En el vocabulario de Sartre, nosotros nos definimos, pues, como materialistas trascendentales, y como estetas. [...] el fin último de las ciencias humanas no es constituir al hombre, sino disolverlo. [...] el verbo "disolver" no supone, de ninguna manera (y aun excluye) la destrucción de las partes constitutivas del cuerpo sometido a la acción de otro cuerpo. [...] Las reducciones que consideramos no serán, pues, legítimas, y ni siquiera posibles, más que con dos condiciones, la primera de las cuales es la de no empobrecer los fenómenos sometidos a reducción [...] En segundo lugar debe estar uno preparado a ver que cada reducción cambia de pies a cabeza la idea preconcebida que podía uno formarse del nivel, sea cual fuere, que uno trata de analizar. [...] La explicación científica no consiste en el paso de la complejidad a la simplicidad, sino en la sustitución de una complejidad menos inteligible por otra más inteligible. (LÉVISTRAUSS, 1970, p.357-358).

En otro lado hemos planteado que podemos entender los caminos de pensadores como Foucault, Deleuze y Guattari como un esfuerzo por superar las limitaciones del estructuralismo gracias a la aplicación de una crítica de carácter nietzscheano sobre tal base (ÁLVAREZ PEDROSIAN, 2011a). La matriz sigue siendo estructural, pero en tanto materia prima a partir de la cual llevar a cabo indagaciones que buscan alcanzar un pensamiento revitalizado. ¿Por qué Nietzsche, y qué hay detrás de ello? En realidad debemos de referirnos a toda la tradición filosófica de procedencia germana, en especial la línea surgida desde Kant, pasando por Hegel, pero haciendo hincapié en la crítica radical que Nietzsche realizara sobre ambos: la recuperación de lo intempestivo, del azar, la contingencia (FOUCAULT, 1994), en definitiva, el devenir múltiple.

Ser y devenir no se oponen, muy por el contrario, el primero puede entenderse como producto relativo al segundo, que es el proceso. El planteo kantiano, y el de la episteme en general del llamado lluminismo, ha sido la crítica, en tanto análisis de las condiciones de posibilidad de la experiencia. La crítica de la crítica efectuada por Nietzsche consta en poner al descubierto lo relativo de los propios principios para efectuar dicha crítica (DELEUZE, 1986). El nihilismo es un primer paso frente a esto, frente a la crisis de los valores, pero un tercer momento está dado como síntesis, como "transvaloración de todos los valores", como creatividad radical de formas de ser, de lo que contemporáneamente llamamos producción de subjetividad. Después de ello, la hermenéutica y la fenomenología 
Siglo deleuziano, siglo de los mapas: cualidades, sentidos y procesos puestos en juego en las cartografías de la subjetividad

irán ganando terreno, hasta encontrarse en el planteo de Heidegger, considerado por Foucault como el principal filósofo del siglo XX.

Si el término "estructuralismo", como hemos planteado, era una etiqueta que incomodaba a sus supuestos representantes, el más reciente de "posestructuralismo" lo es aún más. El prefijo "pos", presente primeramente en "posmodernidad", implicó una suerte de superación de una condición previa sin horizontes, que jamás llegó a concretarse. Los filósofos que se identificaron con dicho término (Baudrillard y Lyotard entre los más importantes) apelaron a caracterizar dicha nueva "condición" a partir de la supuesta muerte de lo real, a partir de la disolución del mecanismo de la representación y con él de la racionalidad moderna. En el caso del segundo, los aspectos más relevantes vienen dados por la imposibilidad de construir teorías totalizadoras, "grandes relatos" explicativos, entre ellos el estructuralismo, el marxismo y la fenomenología, los inmediatamente previos. Pero no podemos dejar de ver que dicha condición fue alcanzada gracias a estas perspectivas y las investigaciones científicas que en ciencias humanas y sociales se fueron generando. Esto mismo ya lo enunciaba Nietzsche, y por qué no el mismísimo Hegel, quien se refería en su momento al "fin de la historia": es la propia racionalidad moderna la encargada de portar los gérmenes de su acabamiento, de su final, sea como consumación o como aniquilamiento.

Ahora bien, nada de esto ha desaparecido, ni la realidad, ni la historia, ni la representación, más bien se han complejizado de forma exponencial. ¿Podemos referirnos a la misma época? Ese no es el problema de importancia, y en tal sentido ni Foucault, ni Deleuze, ni Guattari se identificaron con la pos-modernidad, más bien todo lo contrario. Es por demás llamativo cómo en el contexto intelectual norteamericano de recepción de sus obras, incluida la llamada "geografía posmoderna" (SOJA, 1993; PHILO, 2000), suele confundirse lo que aquí estamos intentado discriminar. El debate modernidad - pos-modernidad no afecta al planteo de nuestros pensadores, a pesar de que en muchas ocasiones hayan sido tildados de pertenecer a la moda denominada con este último término. Considerarlos así es un grave error; más aún, Guattari en particular fue explícitamente contrario a la moda posmoderna por considerarla directamente asociada a planteos capitalistas de corte neoliberal. Pero esto también es parte de la geofilosofía que Deleuze y Guattari 
Siglo deleuziano, siglo de los mapas: cualidades, sentidos y procesos puestos en juego en las cartografías de la subjetividad

(1997) plantearon, y debemos analizar cómo las ideas viajan a partir de trayectos que más o menos las transforman.

En tal sentido, más que pos-estructuralismo, tendríamos que pensar en otras cuestiones como las de mayor relevancia. Pues, como veremos a continuación y en la próxima sección de este artículo, no es fácil dilucidar hasta dónde y qué sentidos los planteos de Foucault, Deleuze y Guattari siguen siendo estructuralistas. Debemos apelar a lo que planteamos más arriba: a un "núcleo duro" conformado por esta matriz en constante proceso de apertura, fuga, deconstrucción. Y como también existen otros filósofos, semiólogos, historiadores y críticos literarios que caen bajo esta denominación tan ambigua, como los casos de Derrida y Barthes en su etapa más avanzada, es aún más necesario hacer el esfuerzo por caracterizar de forma certera el aporte de nuestros tres pensadores fundamentales. En tal sentido, hemos recurrido a una expresión de uno de ellos mismos, de Foucault, que al analizar la perspectiva de Blanchot se refiere al "pensamiento-del-afuera" (FOUCAULT, 1993). Allí creemos radica el gran avance y lo que el contexto contemporáneo en filosofía y ciencias humanas y sociales debe asimilar, lo que viene heredado de la tradición del pensamiento alemán, principalmente procesado por Nietzsche y actualizado en Heidegger: el ser de lo humano no es una esencia, es devenir, y sus componentes, no se encuentran en una suerte de interioridad esencial, sino todo lo contrario, están fuera de él, siempre fuera. Cuando más adentro de la subjetividad profundizamos, más en el afuera, en el "caosmosis" de un "inconsciente maquínico" estaremos (GUATTARI, 1996; DELEUZE Y GUATTARI, 1998).

Las fuerzas proceden siempre del afuera, de una afuera más lejano que toda forma de exterioridad. Al mismo tiempo, no sólo existen singularidades de fuerzas sino también singularidades de resistencia, capaces de modificar esas relaciones, trastocarlas, cambiar el diagrama inestable. $\mathrm{E}$ incluso existen singularidades salvajes, todavía no ligadas, en la línea del afuera, y que se agitan particularmente encima de la fisura... en el punto de fisura, la línea se hace bucle, el "centro de ciclón, justo donde es vivible y donde es por excelencia la Vida». Es como si las velocidades aceleradas, de poca duración, constituyesen «un ser lento» durante un período más largo... Lo más lejano deviene interior al transformarse en lo más próximo: la vida en los pliegues. La habitación central, que ya uno no teme que esté vacía, puesto que pone en ella el sí mismo. Aquí en esa zona de subjetivación, cada cual deviene maestro de su velocidad, relativamente maestro de sus moléculas y de sus 
Siglo deleuziano, siglo de los mapas: cualidades, sentidos y procesos puestos en juego en las cartografías de la subjetividad

singularidades: la embarcación como interior del exterior. (DELEUZE, 1987a, p. 157-158).

Esta desustancialización de la mirada es común tanto a esta tradición fenomenológico-hermenéutica en su versión más radical (pues Husserl, el maestro de Heidegger, será objeto de críticas por nuestros pensadores y antes por su propio discípulo), como al formalismo sofisticado que encontramos en el estructuralismo francés. La mezcla es explosiva: analizar cualquier fenómeno humano de existencia implica abrirse a una multiplicidad en movimiento, donde no hay certezas ni supuestos que queden fijos de una vez para siempre, y donde el acto cognoscente es parte del proceso. El pensar como acontecimiento, como tirada de dados dirán siguiendo a Nietzsche y su genealogía (FOUCAULT, 1994), es una actividad más de la subjetividad en tanto producción de formas de ser a partir de haceres, prácticas, siempre contingentes, condicionadas pero no por ello reducidas a lo dado, más bien todo lo contrario.

\title{
DESARROLLO (MÉTODO Y RESULTADOS): ARTE, CIENCIA Y FILOSOFÍA EN LA ELABORACIÓN DE CARTOGRAFÍAS
}

\begin{abstract}
Mi perspectiva consiste en hacer transitar las ciencias humanas y las ciencias sociales desde los paradigmas cientificistas hacia paradigmas ético-estéticos... De una manera más general, deberá admitirse que cada individuo, cada grupo social vehiculiza su propio sistema de modelización de subjetividad, es decir, una cierta cartografía hecha de puntos de referencia cognitivos pero también míticos, rituales, sintomatológicos, y a partir de la cual cada uno de ellos se posiciona en relación con sus afectos, sus angustias, e intenta administrar sus inhibiciones y pulsiones... Así como un artista toma de sus predecesores contemporáneos los rasgos que le convienen, del mismo modo invito a quien me lee a tomar y rechazar libremente mis conceptos. Lo importante no es el resultado final, sino el hecho de que el método cartográfico multicomponencial pueda coexistir con el proceso de subjetivación y que resulte así posible una reapropiación, una autopoiesis de los medios de producción de subjetividad. (GUATTARI, 1996, p.22-24).
\end{abstract}

¿En qué momento entra en juego aquí el tema de las cartografías y los mapas? Como han señalado variados especialistas en la temática, debemos encontrar primeramente en el planteo del rizoma el hilo conductor (DELEUZE y GUATTARI, 1997a, p.9-32). Eso es lo que hacen Bonta y Protevi (2008, p.109), remitiéndonos directamente al mismo para comprender qué se entiende por mapa 
Siglo deleuziano, siglo de los mapas: cualidades, sentidos y procesos puestos en juego en las cartografías de la subjetividad

desde la perspectiva en cuestión. Gracias a su estudio, además, es posible comprender la relación entre la perspectiva que el "pensamiento nómade", "de la diferencia", quiere alzar más allá del estructuralismo. En un tono claramente nietzscheano, como si se tratara de un manifiesto, el rizoma es planteado por Deleuze y Guattari como una entidad existente en lo dado y como una a ser creada. Sin principio ni fin, más allá de la diferencia entre la permanencia y el cambio, entre lo sincrónico y lo diacrónico, lo objetivo y lo subjetivo, y de todas las demás oposiciones estructuralistas, el rizoma hace alusión a una composición con ciertas características, a partir de una serie de principios.

El primero y el segundo vienen juntos, son el de conexión y heterogeneidad: todo punto del rizoma está conectado con cualquier otra, sin que por ello se homologuen, sino que por el contrario guardan su profunda heterogeneidad, diferencia radical de naturaleza (ideacional, animal, vegetal, mineral, cósmica). El tercer aspecto es el de la multiplicidad, no como simple sumatoria reunida bajo la unicidad, lo Uno, sino como sustantivo. Al respecto es importante hacer foco en el cambio lógico que esto implica: el todo es pensado como parte entre las partes, como particularidad entre las partes que reúne en cuanto que síntesis parcial. Es por ello que los elementos de un mapa no están supeditados a una sola totalidad, sino que cada generalidad esbozada (por ejemplo un nivel, capa o estrato, un "layer") agrupa pero no totaliza. En cuarto término, la ruptura a-significante aparece como principio en el sentido de la acción de fuerzas abstractas que pueden interrumpir, hacer saltar, cortar y desmontar la organicidad del rizoma sin que por ello el mismo no pueda recomenzar, ensamblarse nuevamente (lo que en cartografía podemos ver directamente en la forma tradicional de separar los mapas según coordenadas de forma yuxtapuesta o según niveles co-presentes). Por último, aparecen los principios quinto y sexto también juntos, esta vez como una suerte de oposición: de cartografía y de calcomanía.

La cartografía, en tanto práctica de mapeado, es considerada como la experiencia cognoscente y afectiva primordial. A pesar de las diferencias con el pensamiento taxonómico, sea estructuralismo, sean las llamadas ciencias cognitivas, se comparte esta concepción configuracionista de la subjetividad. Recordemos que la cuestión de los mapas en el ámbito de las ciencias humanas y 
Siglo deleuziano, siglo de los mapas: cualidades, sentidos y procesos puestos en juego en las cartografías de la subjetividad

sociales (entre ellas las de corte cognitivo) aparece primeramente desde la problemática de la mente y el cerebro con la psicología neo-conductista de Tolman (DE LOS RÍOS, 2007). En tal sentido, la modelización era concebida en general en términos de esquemas, siguiendo una clara herencia racionalista cartesiana, con la taxonomía siempre de fondo. La complejidad de los fenómenos urbanos, las grandes metrópolis y demás (aunque la experiencia espacial ya de por sí es relevante frente a la linealidad y uni-dimensionalidad del lenguaje verbal), han llevado a poner especial cuidado en el mapeado. De esta forma, la cartografía aparece como un "universal de la cultura" (STEA, BLAUT y STEPHENS, 1996), al mejor estilo estructuralista.

Como planteamos al comienzo de este ensayo, las perspectivas esbozadas por Foucault, Deleuze y Guattari no pueden desprenderse de fuertes elementos derivados de la misma matriz, aunque al mismo tiempo se lanzan más allá, cual pista de despegue, así como hacia la deconstrucción de lo que estaba implícito, la teoría de la representación de herencia racionalista cartesiana, gracias a la crítica de la crítica de corte nietzscheano. Heidegger fue, sin dudas, el que marcó el camino para una "teoría del habitar" en dicha tradición de pensamiento sobre la subjetividad y el ser (HEIDEGGER, 1994). Recientemente ha sido foco de grandes intereses por parte de arquitectos, urbanistas y diseñadores (SHARR, 2007), así como de investigadores en ciencias humanas y sociales y filósofos.

La cuestión central, en tanto problemática que sirve de hilo conductor en estas tradiciones de pensamiento, es la concepción de la construcción de subjetividad como una obra de arte, entidad estética fruto de un diseño existencial (ÁLVAREZ PEDROSIAN, 2013). Y es, en tal sentido, que el principio de cartografía, opuesto al de calcomanía (asociado a las otras visiones de corte estructural, genética y generativa) es tomado como una de las prácticas fundamentales de "lo vital", como experiencia de apertura, de creación con el afuera. De esta manera aparece la temática de la creación de mapas, como práctica cotidiana, hacer primordial en la inmanencia de la producción de subjetividad.

En tal sentido, la relación con aquellos "collages" que Lévi-Strauss definió como característicos del "pensamiento salvaje", mítico, en tanto forma prístina de la subjetividad (LÉVI-STRAUSS, 1970), aparecen aquí, pero una vez más, proyectados 
Siglo deleuziano, siglo de los mapas: cualidades, sentidos y procesos puestos en juego en las cartografías de la subjetividad

desde el orden, la estabilidad y la taxonomía, al caos, la contingencia y las multiplicidades. La "geografía afectiva" que formula como característica de narrativas mitológicas, como en la terapéutica del shamán y su "eficacia simbólica" (LÉVISTRAUSS, 1994a), está de base pero al mismo tiempo liberada de la analogía como única forma de inferencia del pensamiento, mecanismo de conexión y relación con el mundo. Las cartografías no son una operación de reproducción, de copiado, de calcomanía, sino de generación de algo nuevo sobre aquellas experiencias tomadas de materia prima y transformadas gracias a las nuevas experiencias suscitadas por su construcción. Por esta razón, Deleuze y Guattari hacen hincapié en que el mapa está orientado a la experimentación en lo real, construye inconsciente, contribuyendo a la conexión y potenciando la multiplicidad en lo existente. Es una entidad abierta, desmontable, plural, que surge del encuentro entre las subjetividades y los elementos o materiales considerados para su elaboración, sean orgánicos o inorgánicos, seres u objetos.

Esta geofilosofía, incluye una suerte de geo-gnoseología, que es la que estamos intentando esbozar aquí: una teoría del pensar en cuanto actividad de creación de mapas. Existen diversos ámbitos en los cuales esta tarea puede ser más o menos explicitada, donde puede encontrar mayor o menor receptividad e impulso para su desarrollo. De entre todas ellas, nosotros trabajamos específicamente en la etnografía experimental, focalizada en el análisis de los procesos de subjetivación. En otra oportunidad, hemos analizado lo que para nosotros es una necesaria combinación de estrategias científicas, filosóficas y artísticas para el trabajo sobre la subjetividad, en tanto formas de hacer y ser (ÁLVAREZ PEDROSIAN, 2011b: p.231-270). Estas configuraciones podemos englobarlas bajo la figura tradicional del "anthropos", pero al precio de considerarla como una entidad abierta y plural, en permanente transformación a partir de los componentes y las dinámicas que operan para generar las síntesis relativas, las que reconocemos como contenidos y rasgos de dicho ser en devenir (BOAVENTURA LEITE, 1992; RABINOW, 2003; 2009).

Este debate marca el horizonte contemporáneo de las ciencias antropológicas, tradicionalmente ancladas en la sustancialidad del ser humano primero, y luego en su pura formalización a partir del estructuralismo, como ya 
Siglo deleuziano, siglo de los mapas: cualidades, sentidos y procesos puestos en juego en las cartografías de la subjetividad

hemos planteado. La recuperación de las prácticas específicas, los contenidos concretos que dan sentido a la existencia de lo que somos, pero sin volver a esencialismos ya superados, marca el interés por los trabajos de Foucault, Deleuze y Guattari, así como por los de otros pensadores, científicos y artistas que los han inspirado y que sin ser nombrados explícitamente compartes similares preocupaciones, un mismo horizonte de problemáticas. El peligro puede ser la reificación de este pensamiento, la "domesticación" de lo radicalmente nuevo (GUIGOU, 2005), el retorno a las esencias.

Ciencia, filosofía y artes encuentran su razón de ser como actividades de composición del caos, ideaciones que se desarrollan a partir, contra y gracias a él: función del conocimiento, forma del concepto, fuerza de la sensación. La ciencia elabora functores, la filosofía conceptos, el arte perceptos; la ciencia trabaja con variables, la filosofía con variaciones, el arte con variedades. El conocimiento científico opera a partir de proyectar planos de coordenadas en el caos desacelerándolo, la filosofía construyendo planos de inmanencia o consistencia y el arte de composición, estos dos manteniendo la velocidad e intensidad a velocidades infinitas y su índice de complejidad (DELEUZE y GUATTARI, 1997b).

Ahora bien, Deleuze y Guattari intentan mantener la diferencia entre las tres actividades, y es comprensible. Los ataques y las disputas, principalmente entre ciencia y filosofía, han sido terribles en la historia del pensamiento moderno en Occidente, en especial a partir de la supuesta conquista, área tras área, de cuestiones que eran planteadas especulativamente y que luego alcanzaban un estatus empirista, fenoménico. El caso de las ciencias humanas y sociales es especialmente sensible a ello, y las ciencias geográficas experimentan la correspondiente encrucijada al incluir en su seno la distinción entre lo cultural y lo natural, exactamente igual que las ciencias antropológicas. Unos "planos complejos difíciles de calificar" (DELEUZE y GUATTARI, 1997b, p.219) estarían dándose en las intersecciones entre los tres: hasta allí llega el trabajo de Deleuze y Guattari, avizorando el siglo XXI, el "siglo deleuziano" si tomamos la expresión de Foucault (FOUCAULT, DELEUZE, 1995, p.7) con vistas al futuro.

Pues bien, desde nuestro punto de vista, podemos pensar el trabajo etnográfico, en especial el de corte experimental, abierto a las innovaciones y 
Siglo deleuziano, siglo de los mapas: cualidades, sentidos y procesos puestos en juego en las cartografías de la subjetividad

creatividad rigurosamente trabajada, como una forma de combinación de estas tres actividades, en pos de la elaboración de cartografías de los procesos de subjetivación (ÁLVAREZ PEDROSIAN, 2011b). La ciencia aportaría el trabajo de "discernimiento" de los elementos del mapa, la definición de las cualidades que se toman como variables independientes y dependientes, y las relaciones entre las mismas, dibujando funciones, límites, umbrales, dominios de existencia, etc., todo lo cual permite llevar a cabo un trabajo cuantitativo sobre dicha base si es necesario, tanto numérico como de las propiedades de las mismas formas. Pero esto debe ser complementado con el trabajo de "sobrevuelo" filosófico, pues dichas cualidades consideradas, que hacen a valores y sentidos puestos en práctica en acontecimientos particulares de existencia, necesitan ser problematizados, abiertos a la virtualidad de las variaciones más allá de la correspondencia con lo real. Esto podría pasar en las ciencia naturales también, pero en las humanas y sociales la reflexividad, sea como virtud, sea como carencia, es una condición necesaria para fundamentar el conocimiento generado, y con ello se pone en conexión la creación conceptual, como complemento que tensa la supuesta certeza de aquel plano científico, el de correspondencia, el cartesiano, de base para la geometrización de los fenómenos.

La cartografía por tanto, así entendida, es proyectada en múltiples niveles no necesariamente paralelos, pliegues y remociones de un continuum laberíntico, cavernoso (DELEUZE, 1989a), hecho de variables y constantes que son al mismo tiempo puestas en suspenso, auto-criticadas, y con ello abiertas a la exploración de las variaciones más allá de lo posible. Esto es lo que le otorga rigor y profundidad al análisis, alcance y utilidad a la cartografía más allá de una simple descripción superficial de efectos primarios, observables de forma presumiblemente neutra. La epistemología de Bachelard (2004), retomada por Bourdieu en sus obras, y las diferentes especies de planteos sustentados en la dirección de la reflexividad, dan cuenta de este interés por articular las dos actividades, aunque la disputa entre ciencia y filosofía sigue vigente y el camino por superarla parece pasar por las particularidades de las ciencias sociales (y humanas, podríamos agregar a nuestro criterio), sintetizadas en la forma del bucle de una "ciencia de la ciencia" (BOURDIEU, 2003). 
Siglo deleuziano, siglo de los mapas: cualidades, sentidos y procesos puestos en juego en las cartografías de la subjetividad

Ciertamente Deleuze y Guattari se muestran reacios frente a la reflexión, no debemos olvidarlo, por el temor a la reiteración infinita de "lo Mismo", para usar la terminología de Nietzsche (FOUCAULT, 1997). Descartes no da garantías de ningún tipo para el pensamiento nómade, más allá del plano de coordenadas y la geometrización antigua actualizada de forma analítica en conjunción con la aritmética. La crítica a la "representación clásica", magistralmente llevada a cabo por Foucault en Las palabras y las cosas (1997), no es otra cosa que el proyecto de "destrucción de la metafísica occidental" de Heidegger aplicado en detalle y sobre una base estructuralista sobre el conjunto de las ciencias humanas y sociales, involucrando a las filosofías que le intentaron dar sustento. Esta representación como mecanismo de certeza es el mismo plano de referencialidad, que en la versión positivista se lo buscaba en su versión más pura y simple posible, tendiente a la transparencia. Pero es innegable que con el paso de los años, formulaciones como las del paradigma estético que efectúa Guattari (1996), o la llamada "ontología del presente" del último Foucault (2002), ponen al descubierto este interés por encontrar actividades combinadas entre el conocimiento y el pensamiento, sin anularlos, ciertamente, sino todo lo contrario, enriqueciendo la diferencia y planteando la posibilidad de generar una diversidad de estrategias en el intersticio. Una cosa es innegable: la representación no es algo dado, la referencialidad no está asegurada, el universo no se deja conocer sin más.

Por esa razón, a esto hay que incorporarle el tercer elemento, el trabajo artístico. Si la ciencia pone el discernimiento, la distinción de los elementos y su geometrización; la filosofía el sobrevuelo, las síntesis que pueden articular dichos elementos y darle forma a la vez que proyectarlos más allá de lo dado; el arte nos da las herramientas para la "aprehensión" de todo ello, el trabajo sobre la sensación y la percepción, el diseño y composición tanto de las estrategias de abordaje como de las propias entidades en cuestión. En el caso de los fenómenos humanos de existencia, esto encuentra nuevamente en Nietzsche un referente ineludible: la vida como obra de arte, el ser de lo humano como estética de la existencia.

Es así que planteamos pensar las cartografías de los procesos de subjetivación, compuestas por estos tres tipos de elementos cognoscentes. "Territorios existenciales" en el lenguaje del esquizoanálisis, planteado por ambos 
Siglo deleuziano, siglo de los mapas: cualidades, sentidos y procesos puestos en juego en las cartografías de la subjetividad

(DELEUZE y GUATTARI, 1998), y en especial desarrollado por Guattari desde su experiencia clínica (no etnográfica, pero sumamente afín a la misma) (GUATTARI, 1996), son mucho más que espacios físicos tomados de referencia. Son universos habitados por formas específicas de generación de subjetividad: focos de autocreación (auto-poiesis), así como otras fuerzas de índole abstracta, dispositivos y máquinas que también necesitan ser mapeadas, o más específicamente, aprehendidas por otros medios gráficos como los diagramas.

No es por casualidad, por tanto, que en el ámbito de las ciencias geográficas haya existido una gran repercusión de la obra de nuestros pensadores, en especial bajo la imagen de Deleuze, pero que creemos no puede opacar la existencia de una cosmovisión compartida con Foucault y Guattari (inclusive, algunos críticos han manifestado que los trabajos con el segundo llegaron a ser de alguna forma perjudiciales por haberlo apartado de la filosofía y contaminado con jerga cientificista). Las cartografías alternativas, utilizadas como herramientas para la generación de tejido social, comunitario, en prácticas colectivas de creación de conocimiento y aprehensiones estéticas, se orientan en este sentido (STALLMANN, 2012), incluso haciendo uso de imágenes satelitales como soportes para nuevas prácticas (PROPEN, 2009, p.127).

Desde las ciencias humanas y sociales, a su vez, esto ha llevado a un creciente interés por la elaboración de cartografías como herramientas metodológicas en la investigación (DIEZ TETAMANTI y ESCUDERO, 2012), gracias a la reincorporación o revalorización de las problemáticas espaciales presentes en su campo (PICKLES, 1985; WARF y ARIAS, 2009). Como hemos planteado, este giro espacialista de la epistemología contemporánea puede ser aún algo de mucho mayor alcance: una geo-gnoseología asociada a una onto-topología (para usar una expresión del propio Sloterdijk (2011), al analizar la forma en que el mismo Heidegger formulaba la cuestión del ser), al hacerse explícito el carácter fundamental de la espacialidad en la forma de concebir los procesos de subjetividad en todas sus dimensiones y alcances.

\section{DESARROLLO (DISCUSIÓN): RIZOMA, PATCHWORK, DIAGRAMA, CUADRO Y GUIÓN: algunas consideraciones etnográficas}


Siglo deleuziano, siglo de los mapas: cualidades, sentidos y procesos puestos en juego en las cartografías de la subjetividad

"¿Qué clase de espacio estamos tratando de mapear, o bien, de qué estamos hablando cuando hablamos sobre el espacio de una manera deleuziana?, y, además, ¿qué tipo de espacio es el que producimos en ese mapeo?"1 (DEWSBURY Y THRIFT, 2005, p.100). Aquél "método cartográfico multicomponencial" al que hace referencia Guattari y que citamos al comienzo del apartado precedente (GUATTARI, 1996, p.22-24), como expresión fundamental de su "paradigma estético", que podemos entender como elaborado gracias a functores, conceptos, perceptos y otro tipo de ideas elaboradas, da como resultado una diversidad de entidades gráficas, para nada excluyentes. En un punto, podemos hasta pensar que las mismas son elementos de composición de composiciones mayores, no totalizaciones, recordémoslo (el todo es una parte entre las partes y no un resultado superior). Las cartografías de la subjetividad están hechas de tal forma que poseen regiones rizomáticas, secuencias combinadas que se asemejan a los patchwork, entidades abstractas que dibujan un diagrama que atraviesa en otra dimensión toda la composición con sus máquinas abstractas operando y demás.

Así, en nuestra perspectiva, las cartografías de subjetividad inconscientes deberían convertirse en los complementos indispensables de los sistemas de racionalidad que tienen vigencia en las ciencias, la política y todas las otras regiones del conocimiento y la actividad humana. ¡Los complementos o, de no ser así, los instrumentos de contestación y transformación! En fin, por lo menos... la lectura de zonas de hiper-complejidad, cuya elucidación ya no se relaciona con tratamientos lógicos habituales. ¿Por qué? Ante todo porque el mapa pierde aquí su vocación primera de tener que representar un territorio... [a favor de] los procedimientos cartográficos capaces de posicionar singularidades y procesos de singularización, lo que yo llamaría: pragmáticas ontológicas. Y sería vano en esta ocasión clamar por el fracaso de la racionalidad, porque, en cierto sentido, a largo plazo, se trata justamente de su consolidación. (GUATTARI, 2000, p.52).

Podemos decir que existen tres tipos de líneas en una cartografía de los procesos de subjetivación: las de segmentaridad (duras, que estratifican, organizan, significan, en fin, territorializan), las de micro-devenires (flexibles, abiertas a los encuentros, por donde son posibles desterritorializaciones relativas), y las líneas de

\footnotetext{
1 "What kind of space are we trying to map, or, what are we talking about when we talk about space in a Deleuzian manner; and, further, what kind of space do we produce in that mapping?"
} 
Siglo deleuziano, siglo de los mapas: cualidades, sentidos y procesos puestos en juego en las cartografías de la subjetividad

fuga (de transformación, desterritorialización absoluta) (DELEUZE y PARNET, 1997, p.141-142). Y es que: “... quizá debamos describir el organismo no como un objeto autocontenido, con límites, sino como una línea -o mejor aún como un haz de líneas- que continuamente desborda cualquier contorno" (INGOLD, 2012, p.28). Siguiendo al geógrafo sueco Hägerstrand, Ingold encuentra la noción rizomática del devenir en los trazos que toda entidad (humanos, plantas, otros animales, cosas, etc.) va dibujando temporalmente, "gran tapiz de la Naturaleza que la historia está tejiendo" (HÄGERSTRAND en INGOLD, 2012, p.29); trayectos que se conectan y desconectan (GUIGOU, 2004).

Además de líneas hay regiones, umbrales y toda una topología. Es bajo la perspectiva del esquizoanálisis donde la cuestión de las cartografías alcanza su mayor profundización, si bien ronda más o menos explícitamente por la arqueología, la genealogía y la microfísica del poder de Foucault, y otras configuraciones gnoseológicas de Deleuze y Guattari, como el llamado por este último, paradigma estético. Las cartografías esquizoanalíticas -herederas del "more geométrico" de Spinoza aplicado a la entonces denominada ética, con sus atributos, modos, afectos y nociones comunes (RAWES, 2008, p.62-90) - se proponen como una tarea por demás atrevida y difícil, en el sentido de "pensar lo impensado", que movió a varios de los referentes de nuestros pensadores, como Nietzsche principalmente.

Las entidades que componen estas cartografías escaparían a la posibilidad de delimitaciones "claras y distintas" y su ordenamiento en un "cuadro general", para usar la terminología del racionalismo cartesiano, a los requerimientos de una correspondencia entre un territorio y su mapa, lo existente objetivamente y la construcción subjetiva que intenta tomarlo en su forma certera. Guattari señala algunos de estos elementos: a) según funciones clásicas de representación y denotación: figuras de expresión, entidades mentales, objetos referidos (reales o virtuales), b) según una función de existencialización: índices intensivos, operadores diagramáticos, cristales de singularización, puntos de bifurcación, entre otras acepciones, a veces como sinónimos, otras más o menos semejantes (GUATTARI, 2000, p.52).

Lo más relevante parece ser la oposición entre cartografía y calco, en tanto este último: "simplemente representa las (actuales) propiedades de equilibrio / 
estado estacionario / sistema estable"2 (BONTA y PROTEVI, 2008,p. 67). Asimismo, es significativo el planteo de considerar tanto la extensión como la intensión, la intensidad de las entidades en cuestión; planteo que podemos rastrear fácilmente desde los estudios sobre el movimiento y la "duración" en Bergson (DELEUZE, 1996, p.37-38). La "latitud" de la intensidad de los afectos, y la "longitud" como la velocidad de sus elementos materiales (BONTA y PROTEVI, 2008, p.68), lo cual, si volvemos a Bergson, corresponde a las dos series de multiplicidades: las subjetivas y las objetivas. Ciertamente, esto no puede considerarse como una nueva versión de la dicotomía espacio/tiempo, más bien todo lo contrario. Los estudios sobre Bergson por parte de Deleuze tienen dos grandes momentos: aquél inicial en la época de la recuperación de una "historia menor de la filosofía" (sus monografías sobre los filósofos que toma de base) (DELEUZE, 1996), y posteriormente sus estudios sobre el cine (en especial en DELEUZE, 1987b). Y la reflexión geográfica adopta esta inquietud por lo espacio-temporal como entidad unívoca a la hora de pensar las cartografías rizomáticas, y por tanto, orientadas hacia el devenir de los acontecimientos humanos y no humanos (MAY y THRIFT, 2001).

Como lo recuerdan Bonta y Protevi (2008, p.68), el mapa y su arte, la cartografía, son una forma de narrar, por momentos limitada a los regímenes de signos a diferencia de los "diagramas" de "máquinas abstractas", otras incluyéndolos como práctica genérica de la con-formación. En este punto debemos retomar las caracterizaciones que Deleuze y Guattari realizan de la ciencia, la filosofía y el arte, en lo relativo a los "planos" que proyectan en, contra y gracias al caos: de coordinación, consistencia o inmanencia y composición respectivamente. El mapa guarda relaciones referenciales en el primer sentido, escapa a ellas y se abre a la problematicidad de la virtualidad en el segundo, y es mucho más que esquema o diagrama al incluir múltiples formas según estilos y géneros según soportes y materiales de expresión diferentes en el tercero.

Un espacio actual y otro virtual, conectado por las intensidades, entre las materialidades captables por una geometría euclideana y los flujos desterritorializantes no-métricos (DELANDA, 2005), no son igualmente susceptibles

\footnotetext{
2 “[...] simply represents the (actual) properties of equilibrium / steady state / stable systems [...]"
} 
Siglo deleuziano, siglo de los mapas: cualidades, sentidos y procesos puestos en juego en las cartografías de la subjetividad

de ser cartografiados, o dicho de otra manera, no son entidades de la misma naturaleza y por consiguiente tampoco se aprehenden de la misma forma. Ahora bien, más que excluirse, se interpenetran, pues los territorios están surcados por los flujos y sus intensidades (WEST PAVLOV, 2009). La geometría y el cálculo infinitesimal que asoma por detrás del plano isomorfo cartesiano, pone al descubierto la dinámica del devenir, cada vez más prioritaria para las propias ciencias que se asoman más allá de la estabilidad (BONTA Y PROTEVI, 2008), sea la termodinámica y las irreversibles bifurcaciones con sus nuevos estados de la materia en puntos distantes del equilibro (PRIGOGINE, 1995, p.47), o el medioambiente y su diseño antropológico más allá del dualismo y la linealidad de la inter-acción (INGOLD, 2012, p.49).

Podemos encontrar zonas y regiones de relativa estabilidad, susceptibles de mapear a partir de planos más o menos secantes, pero "el continuum es cavernoso" (DELEUZE, 1989a), el universo se expresa en forma barroca con constantes pliegues de la materia, repliegues del "alma" y des-pliegues, en una topología de estratos solapados, removidos y no necesariamente paralelos. La geometría de Leibniz se plantea desde esta otra lógica, desde la cual como es sabido no hace falta negar la eficacia de la medición y la aritmética aplicada a las formas, la geometría analítica de Descartes. Más bien se la complementa, se la sitúa en su umbral de existencia específica, más allá y más acá de la cual nos aventuramos en las regiones donde no reina sin más: en los infinitos puntos que median entre cada punto del plano, las derivadas que muestran cómo infinitesimalmente no podemos pensar en forma lineal, sino más bien curvada.

Estas consideraciones, en torno al pliegue, el continuum no isomorfo y lo que caracterizaron como espacios "lisos" y "estriados", "en absoluto simétricos" (DELEUZE y GUATTARI, 1997a, p.484), ha despertado los mayores desafíos para la epistemología y ontología de la geografía. Más allá de juegos retóricos vacíos, lo interesante aquí es poder aprehender, pensar y conocer estas entidades que hemos visto caracterizan las cartografías de los procesos de subjetivación, las cuales en términos convencionales hacen coincidir el presente puro con la no-existencia -tema ya planteado en la lógica del sentido, en tanto este persiste e insiste, más que existe (DELEUZE, 1989b), y en la naturaleza del concepto filosófico, en tanto 
Siglo deleuziano, siglo de los mapas: cualidades, sentidos y procesos puestos en juego en las cartografías de la subjetividad

intempestividad o acontecimiento puro en el "Erewhon" de Samuel Butler (DELEUZE, 1988, p.33-34)-: "Lugar y deslugaridad ya no se oponen, como los geógrafos humanistas creían. De aquí en adelante, un lugar es a la vez un aquíahora y un en-ninguna-parte ${ }^{3}$ (DOEL, 2005, p.124).

En los últimos años, y a partir de las relaciones que los investigadores de la obra de Deleuze empezaron a establecer entre sus obras, así como por el desarrollo teórico derivado directamente del campo de producción audiovisual, la lógica de este tipo de mediaciones comenzó a ser tomada cada vez más en cuenta como la más apropiada para dar cuenta de tal heterogénesis de elementos constituyentes y la complejidad de los montajes necesarios. A ello se suma la necesidad de poner en evidencia el carácter fundamentalmente procesual de los fenómenos, la naturaleza del devenir que reina por debajo y entre los intersticios de las "cristalizaciones existenciales".

Esto no quiere decir que los investigadores de los procesos de subjetivación tengamos que dejar la escritura y ponernos a hacer vídeos y cine, eso sería una lectura muy ingenua. La cuestión es más complicada: la propia narrativa contemporánea se va fuertemente afectada por el lenguaje audiovisual (DE LOS RíOS, 2007), los "libro-máquina" se ven inspirados en la forma en que guionistas, camarógrafos y directores elaboran su trabajo. Quizás tengamos que cambiar el uso de los términos, pues corremos el peligro de estar frente a una corriente simplificación: por narrativa no pensamos solo en aquellas composiciones que siguen estructuras generalmente asociadas a géneros literarios clásicos y modernos, sino que debemos ampliar la definición para considerar otras formas de ensamblaje y diseño en general mucho más complejos. El "dispositivo cinematográfico", justamente, es lo que habilitó, al punto de constituirse una suerte de "divergencia" entre cine y narración (GALUPPO, 2012), siendo posible un tipo de experiencia y por consiguiente unas experimentaciones que llevan al límite, subvierten y traen a la existencia nuevas sensibilidades.

En los orígenes del cine podemos encontrar ambos caminos: el pegado a la narrativa clásica en general por parte de los norteamericanos, o la apertura a las

\footnotetext{
3 "Place and placelessness are no longer opposed, as the humanistic geographers believed. Hereinafter, a place is both NowHere and No Where."
} 
Siglo deleuziano, siglo de los mapas: cualidades, sentidos y procesos puestos en juego en las cartografías de la subjetividad

nuevas posibilidades que la técnica trajo, como el caso de los europeos, sean franceses o soviéticos: "El límite, desde aquí, es el fotograma vacío, el blanco y el negro que se alternan... solo el aparente parpadeo del proyector, la pulsación lumínica y sus ráfagas vertiginosas que constituyen el elemento base del dispositivo" (GALUPPO, 2012, p.26). Antes de llegar a este límite, nos encontramos con la posibilidad de sobreponer imágenes, alterar los fotogramas en el laboratorio, componer finalmente en el montaje el devenir con perceptos sonoros y visuales, operar con narrativas múltiples en niveles y secuencias. Todo ello constituye una cartografía espacio-temporal, una "proyección topográfica" (CONLEY, 2007), donde se combinan los regímenes de enunciación y de visibilidad con sus propias lógicas, tal como lo planteó Foucault y fue retomado por Deleuze en el estudio de su pensamiento, en la labor de quien fue, según su expresión, un "nuevo cartógrafo" (DELEUZE, 1987a).

En tal sentido, podemos comprender el experimento de la llamada "ontografía correlativa" llevada a cabo recientemente por geógrafos y artistas en un gesto por demás etnográfico, intentando hacer una cartografía de los problemas ambientales y de salud del Montreal contemporáneo (CALVELLI, 2011). Fotografías de sitios georeferenciados, junto a indicadores sociales, económicos, sanitarios y culturales, intentan aprehender los fenómenos humanos allí involucrados de una forma más eficaz que las convencionales. Las fotografías escapan a la pura representatividad, son, efectivamente, obras de arte, aprehensiones de perceptos en el sentido que Deleuze y Guattari caracterizan al mismo. En una suerte de neo-realismo o hiperrealismo, estas imágenes visuales realizadas a partir de los paisajes, objetos y escenarios existentes son un esfuerzo por des-naturalizar la mirada, provocar el extrañamiento en el observador, tal como lo efectúa el ejercicio de la etnografía (ÁLVAREZ PEDROSIAN, 2011b): contrastes que ponen en juego las intensidades y heterogeneidad de los componentes, las paradojas y dislocamientos de lo que parece difícil de concebir.

No se intenta reproducir el efecto naturalista, por eso aludimos al neorealismo cinematográfico como ejemplo de cómo se puede tratar la realidad de una forma no-representacional, reducida a situaciones sensoriomotrices, a formas habituales de percepción, etc., lo que Deleuze trabajo justamente en relación a la 
Siglo deleuziano, siglo de los mapas: cualidades, sentidos y procesos puestos en juego en las cartografías de la subjetividad

"imagen-tiempo" en sus estudios sobre el cine (DELEUZE, 1987b). En el experimento de Calvelli, podemos ver una puesta en práctica de la forma en que se intenta articular la ciencia, la filosofía y el arte en la producción de conocimiento contemporáneo, en el sentido en que lo hemos planteado en la sección anterior, y no por casualidad se realiza tomando como base a la práctica cartográfica.

También desde el oficio de los hacedores de espacios y espacialidades (diseño arquitectónico y urbanístico), se toma en cuenta la existencia de diferentes planos y mapas a partir de la heterogeneidad de agentes y subjetividades más en general involucradas en la tarea de diseño y construcción. En tal sentido, cada cartografía, aunque corresponda -desde un punto de vista científico, referencial- a una misma casa, lo hará de diferentes formas, según diferentes "planos". Pues en definitiva, dicha unidad referida, la casa, no deja de ser múltiple (es una para los habitantes, otra para los contratistas, otra para los albañiles, otra para los constructores, etc.) (BALLANTYNE, 2007, p. 40). La creación y utilización son inseparables del mapa, en tanto que práctica generadora de un saber en y para la experiencia.

\section{CONSIDERACIONES FINALES}

Los "map studies" recogen varias de las cuestiones fundamentales que hemos intentado trabajar aquí. Algunas problemáticas son comunes a todo el espacio epistemológico de las ciencias humanas y sociales, otras se acercan más decididamente a las cuestiones relativas a la tecnología y la tecno-ciencia, especialmente por el rol que ocupa la ingeniería de la imagen en el quehacer cartográfico y la relevancia de los recursos allí referenciados. $Y$ como sucede con la etnografía, la relación entre el conocimiento científico, la producción artística y la conceptualización filosófica también está en el tapete, como hemos visto en profundidad.

Según Dodge, Perkins y Kitchin (2009), estos estudios (que a su vez influyen a los demás campos disciplinarios que adoptan las cartografías como metodología, epistemología y hasta ontología de trabajo), se plantean una serie de problemáticas que marcan el horizonte de indagaciones contemporáneas. En primer lugar, la cuestión de las interfaces, de la imagen visual y la pantalla, en lo que serían "screen 
Siglo deleuziano, siglo de los mapas: cualidades, sentidos y procesos puestos en juego en las cartografías de la subjetividad

spaces". En segundo término, la cuestión de los algoritmos y los mapeos, nos vuelve a traer el problema de la articulación de la tarea científica, la digitalización y su utilización. Luego, vuelve a aparecer la cuestión de la visualidad, pero ahora considerando la dimensión mediacional en su conjunto, desde la cultura visual y las implicancias que la trascienden. Posteriormente se plantea el problema de la autoría de los mapas, algo que la producción en diferentes contextos sociales y políticos ha ido problematizando cada vez más, y en términos epistemológicos también tuvo, principalmente a Foucault, como uno de los pioneros en disolver tal categoría esencialista, la de "autor". El quinto dominio de cuestiones de interés, tiene que ver con las infraestructuras, en tanto el mapa es él mismo considerado como un insumo básico en la llamada sociedad de la información, lo cual está generando grandes transformaciones.

De ello se desprenden, a su vez, una serie de desafíos y oportunidades, creemos, en la senda de lo planteado en este artículo, lo que pone de manifiesto la importancia que la obra de Foucault, Deleuze y Guattari ha tenido en nuestra contemporaneidad: la materialidad (asociada a la virtualidad y los soportes de información que se manejan), la economía política del mapeado (como práctica que genera transformaciones en el mundo en el que se la realiza), los afectos (en relación a lo que hemos visto sobre la aprehensión estética y su relación con las formas de conocimiento y pensamiento) y finalmente la etnografía, en tanto abordaje que permite procesar de manera privilegiada dichas prácticas desde la emergencia y los acontecimientos en que los sujetos creadores estamos inmersos, en la pluralidad de perspectivas puestas en juego.

Pensar al mapeo como un conjunto de prácticas, conlleva concebir los diferentes "momentos" de creación y utilización etnográficamente, como procesos que determinan a los productos, los mapas. Pero ello debe hacerse más allá de cualquier visión esencialista de la subjetividad humana, de lo contrario volveríamos a caer en todo aquello que nuestros pensadores han tratado de dejar al descubierto, en la senda de la filosofía de los procesos de subjetivación, gracias a sus perspectivas arqueológicas, genealógicas, topológicas, rizomáticas y estéticas. Es así que Dodge, Perkins y Kitchin (2009), encaminan su manifiesto en tal sentido, 
Siglo deleuziano, siglo de los mapas: cualidades, sentidos y procesos puestos en juego en las cartografías de la subjetividad

sobre lo que las prácticas de mapeo generan como productoras de subjetividad, creadoras de formas ontológicas en sí mismas:

\begin{abstract}
En vez de la usual y a veces estéril enumeración de sectores particulares, contextos, culturas, lugares o incluso tipos de mapas o productos, argumentamos que focalizarse en los procesos claves tiene más probabilidades de revelar los aspectos críticos del mapeo. Como tal, ofrecemos una lista tentativa de momentos de mapeo que pensamos son significativos y dignos de estudio: (i) lugares y tiempos de fallas, (ii) puntos de cambio, (iii) ritmos espacio-temporales de desempeño del mapa, (iv) las memorias del mapeo, (v) la praxis académica; y (vi) recientes involucramientos creativos con la práctica de mapeo." (DODGE, PERKINS y KITCHIN, 2009, p.234).
\end{abstract}

Si bien producto y proceso pueden pensarse diferencialmente, y debemos hacerlo, no por ello dejan de ser cuestiones profundamente relacionadas, y es el interés por la etnografía experimental lo que pone en evidencia la convergencia epistemológica y ontológica de los cartógrafos profesionales de mayor conceptualización y creatividad con aquellas ciencias, filosofías y artes que desde sus propios trayectos se orientan hacia este encuentro por demás fructífero y alentador: el de un siglo deleuziano, un siglo de los mapas.

\title{
REFERÊNCIAS
}

ÁLVAREZ PEDROSIAN, Eduardo. El afuera en el adentro. Estética, nomadismo y multiplicidades. Montevideo: LICCOM-Universidad de la República, 2011a.

. Etnografías de la subjetividad. Herramientas para la investigación. Montevideo: LICCOM-Universidad de la República, 2011b.

El ser habitado: diseño existencial y procesos de subjetivación. In: Actas electrónicas del III Congreso Iberoamericano de Teoría del Habitar: Entre prácticas, materialidades y significaciones. Montevideo: Asociación

\footnotetext{
4 "Instead of the usual and sometimes sterile enumeration of particular sectors, contexts, cultures, places or even types of map or product, we argue that a focus on key processes is more likely to reveal critical aspects of mapping. As such, we offer a tentative list of mapping moments that we think are significant and worthy of study: (i) places and times of failures, (ii) points of change, (iii) timespace rhythms of map performance, (iv) the memories of mapping, (v) academic praxis; and (vi) newly creative engagement with mapping practice."
} 
Siglo deleuziano, siglo de los mapas: cualidades, sentidos y procesos puestos en juego en las cartografías de la subjetividad

Latinoamericana de Teoría del Habitar - Facultad de Arquitectura de la Universidad de la República, 2013.

BACHELARD, Gaston. La formación del espíritu científico. Contribución a un psicoanálisis del conocimiento objetivo. México/D.F.: Siglo XXI, 2004.

BALLANTYNE, Andrew. Deleuze \& Guattari for architects. London - New York: Routledge, 2007.

BOAVENTURA LEITE, Ilka. Produzir o texto, polir o olhar. In: BOAVENTURA LEITE, llka. (Org.) Ética e estética na antropologia. Florianópolis: Programa de PósGraduação em Antropologia Social da UFSC, CNPq, 1992, p. 41-46.

BONTA, Mark. PROTEVI, John. Deleuze and Geophilosophy. A Guide and glossary. Edinburgh: Edinburgh University Press, 2008.

BOURDIEU, Pierre. El oficio de científico. Ciencia de la ciencia y reflexividad (Curso del Collège de France 2000-2001). Barcelona: Anagrama, 2003.

CALVELLI, John. Experiments in Correlative Ontography: the visualization of environmental and ontological injustice. In: CAQUARD, Sébastien. VAUGHAN, Laurene. CARTWRIGHT, William. (Orgs.). Mapping environmental Issues in the City. Arts and cartography cross perspectives. Berlin-Heidelberg: Springer, 2011, p. 209-225.

CONLEY, Tom. Cartographic cinema. Minneapolis - London: University of Minnesota Press, 2007.

DELANDA, Manuel. Space: Extensive and Intensive, Actual and Virtual. In: BUCHANAN, lan. LAMBERT, Gregg. (Orgs.). Deleuze and Space. Edinburgh: Edinburgh University Press, 2005, p. 80-88.

DELEUZE, Gilles. Nietzsche y la filosofía. Barcelona: Anagrama, 1986.

Foucault. México: Paidós, 1987a.

La imagen-tiempo. Estudios sobre cine 2. Barcelona: Paidós, 1987b.

Diferencia y repetición. Madrid: Júcar, 1988.

. El pliegue. Leibniz y el barroco. Barcelona: Paidós, 1989a. 
Siglo deleuziano, siglo de los mapas: cualidades, sentidos y procesos puestos en juego en las cartografías de la subjetividad

La lógica del sentido. Barcelona: Paidós, 1989b.

El bergsonismo. Madrid: Teorema, 1996.

DELEUZE, Gilles. GUATTARI, Félix. Mil mesetas. Capitalismo y esquizofrenia II. Valencia: Pre-textos, 1997a.

DELEUZE, Gilles. GUATTARI, Félix. ¿Qué es la filosofía? Barcelona: Anagrama, 1997b.

DELEUZE, Gilles. GUATTARI, Félix. El Anti-Edipo. Capitalismo y esquizofrenia. Barcelona: Paidós, 1998.

DELEUZE, Gilles. PARNET, Claire. Diálogos. Barcelona: Pre-textos, 1997.

DE LOS RÍOS, Valeria. Cartografía salvaje: mapa cognitivo y fotografías en la obra de Bolaño. Taller de Letras, Santiago de Chile, v.41, p. 69-81, 2007.

DEWSBURY, John David. THRIFT, Nigel. "Genesis Eternal": After Paul Klee. In: BUCHANAN, lan. LAMBERT, Gregg. (Orgs.) Deleuze and space. Edinburgh: Edinburgh University Press, 2005, p.89-108.

DIEZ TETAMANTI, Manuel. ESCUDERO, Beatriz. (Orgs.). Cartografía social: investigaciones $\mathrm{e}$ intervención desde las ciencias sociales: métodos y experiencias de aplicación. Comodoro Rivadavia: Universidad de la Patagonia, 2012.

DODGE, Martin. KITCHIN, Rob. PERKINS, Chris. Mapping modes, methods and moments. A manifesto for map studies. In: DODGE, Martin. KITCHIN, Rob. PERKINS, Chris. (Orgs.). Rethinking Maps. London: Routledge, 2009, p. 220-243.

DOEL, Marcus A. Un-glunking geography: spatial science after Dr Seuss and Gilles Deleuze. In: CRANG, Mike. THRIFT, Nigel. (eds) Thinking Space. London - New York: Routledge, 2000. 5, p. 117-135.

FOUCAULT, Michel. El pensamiento del afuera. Valencia: Pre-textos, 1993.

FOUCAULT, Michel. Nietzsche, la genealogía, la historia. In: FOUCAULT, Michel. Microfísica del poder. Barcelona: Planeta-Agostini, 1994, p. 7-29.

FOUCAULT, Michel. Las palabras y las cosas. Una arqueología de las ciencias humanas. México: Siglo XXI, 1997. 
Siglo deleuziano, siglo de los mapas: cualidades, sentidos y procesos puestos en juego en las cartografías de la subjetividad

FOUCAULT, Michel. ¿Qué es la llustración? Córdoba (Arg.): Alción Editora, 2002.

FOUCAULT, Michel. DELEUZE, Gilles. Theatrum philosophicum \& repetición y diferencia. Barcelona: Anagrama, 1995.

GALUPPO, Gustavo. Dispositivo cinematográfico y narración. Apuntes sobre una divergencia. In: LA FERLA, Jorge. REYNAL, Sofía. (Orgs.). Territorios audiovisuales: cine, televisión, documental, instalación, nuevas tecnologías. Buenos Aires: Libraria, 2012.

GUATTARI, Félix. Caosmosis. Buenos Aires: Manantial, 1996.

GUATTARI, Félix. Cartografías esquizoanalíticas. Buenos Aires: Manantial, 2000.

GUIGOU, L. Nicolás. Cartografías antropológicas. Trayectos, conexiones y desconexiones. Montevideo: La Gotera, 2004.

GUIGOU, L. Nicolás. El pensamiento domesticado: Gilles Deleuze y la antropología. Comunidade Virtual de Antropologia, v.19, 2005. Disponible en www.antropologia.com.br/colu/colu19.htm. Acceso en 12 Feb 2014.

HEIDEGGER, Martin. Construir, habitar, pensar. In: HEIDEGGER, Martin. Conferencias y artículos. Barcelona: Ed. del Serbal, 1994, p. 127-142.

INGOLD, Tim. Ambientes para la vida. Conversaciones sobre humanidad, conocimiento y antropología. Montevideo: Trilce - FHCE-SCEAM-UdelaR, 2012.

LAKATOS, Imre. La metodología de los programas de investigación científica. Madrid: Alianza, 1989.

LÉVI-STRAUSS, Claude. El pensamiento salvaje. México: FCE, 1970.

La eficacia simbólica. In: Antropología estructural. Barcelona: Altaya, 1994a., p. 211-227.

LÉVI-STRAUSS, Claude. La noción de estructura en etnología. In: Antropología estructural. Barcelona: Altaya, 1994b, p. 299-337.

MAY, Jon. THRIFT, Nigel. Introduction. In: MAY, Jon. THRIFT, Nigel. (Orgs.). Timespace. Geographies of temporality. London - New York: Routledge, 2001. 1, p. 1-46. 
Siglo deleuziano, siglo de los mapas: cualidades, sentidos y procesos puestos en juego en las cartografías de la subjetividad

MORIN, Edgar. El pensamiento subyacente (paradigmatología). In: MORIN, Edgar. EI Método IV. Las ideas. Su hábitat, su vida, sus costumbres, su organización. Madrid: Cátedra, 1992, p. 216-244.

PHILO, Chris. Foucault's geography. In: CRANG, Mike. THRIFT, Nigel. (Orgs.). Thinking space. London - New York: Routledge, 2000, p. 205-238.

PICKLES, John. Phenomenology, science and geography. Spatiality and the human sciences. Cambridge: Cambridge University Press, 1985.

PRIGOGINE, llya. ¿El fin de la ciencia? In: Fried Schnitman, Dora. (Orgs.). Nuevos paradigmas, cultura y subjetividad. Buenos Aires: Paidós, 1996, p. 37-60.

PROPEN, Amy. D. Cartographic representation and the construction of lived worlds: understanding, cartographic practice as embodied knowledge. In: DODGE, Martin. KITCHIN, Rob. PERKINS, Chris (Orgs.). Rethinking maps. London: Routledge, 2009, p. 113-130.

RABINOW, Paul. Anthropos today. Reflections on modern equipment. Princeton: Princeton University Press, 2003.

RABINOW, Paul. Pasos hacia un laboratorio antropológico. Revista de Antropología Experimental, Jaén, v.9, p. 137-151, 2009. Disponible en http://revista.ujaen.es/huesped/rae. Acceso en 17 Feb 2014.

RAWES, Peg. Space, geometry and aesthetics. Through Kant and towards Deleuze. New York: Palgrave MacMillan, 2008.

SHARR, Adam. Heidegger for architects. London - New York: Routledge, 2007.

SLOTERDIJK, Peter. "Al Dasein le es propia una tendencia esencial a la cercanía" (Nota marginal sobre la doctrina de Heidegger del lugar existencial). In: Sin salvación. Tras las huellas de Heidegger. Madrid: Akal, 2011, p. 263-268.

SOJA, Edward. Geografias pós-modernas: a reafirmação do espaço na teoria social crítica. Rio de Janeiro: Zahar, 1993.

STALLMANN, Timothy. Alternative cartographies building collective power. 2012. Thesis of Master of Arts - Department of Geography, University of North Carolina at Chapel Hill, Chapel Hill, NC, 2012. 
STEA, David. BLAUT, James, M. STEPHENS, Jennifer. Cognitive Mapping and culture. Mapping as a cultural universal. In: PORTUGALI, Juval. (Orgs.). The construction of cognitive maps. Dordrecht - Boston - London: Kluwer Academic Publishers, 1996, p. 345-360.

WAHL, François. ¿Qué es el estructuralismo? Filosofía. La filosofía antes y después del estructuralismo. Buenos Aires: Losada, 1975.

WARF, Barney. ARIAS, Santa. Introduction: the reinsertion of space in the humanities and social sciences. In: WARF, Barney. ARIAS, Santa. (Orgs.)s The spatial turn. Interdisciplinary perspectives. London - New York: Routledge, 2009, p. 1-10.

WEST-PAVLOV, Russell. Space in theory. Kristeva, Foucault, Deleuze. Amsterdam - New York: Rodopi, 2009. 